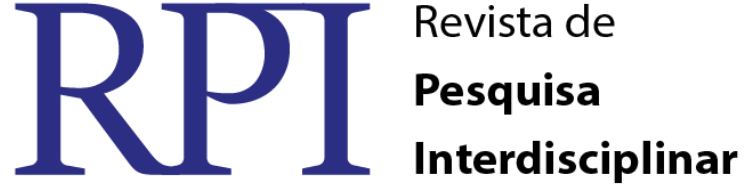

\section{A INTERNET COMO FONTE DE ANÁLISE PARA O PIBID E A FORMAÇÃO INICIAL DOCENTE}

\author{
Daniela Cristina Pereira Ramos - UFCG/CFP \\ Risoneide silva de Araújo - UFCG/CFP \\ Rosemere Olímpio de Santana - UFCG/CFP
}

\begin{abstract}
RESUMO
Considerando a importância que o Programa Institucional de Bolsa de Iniciação á docência (PIBID) vem adquirindo desde sua criação, com a finalidade de estimular á iniciação á docência, e contribuir com o desenvolvimento e melhoria do ensino na rede básica de educação, objetivamos nesta pesquisa destacar os processos e discursos que envolvem a formação inicial docente promovida pelo programa produzidos pelos bolsistas de iniciação a docência nas redes sociais. No entanto, a análise aqui empreendida se deu através da aplicação de questionários semi estruturados aos bolsistas de iniciação a docência do subprojeto de História, Física, Química, Matemática, Biologia, Pedagogia, Letras, Geografia, cuja transcrição respeitou a escrita dos entrevistados, análise de materiais como imagens e relatos presentes nas páginas da internet PIBID Depressão, e Grupo Nacional do PIBID no Facebook. Além dessa metodologia analisou-se informações através de documentos públicos sobre o PIBID, tais como: documentos oficiais, como relatórios de gestão emitidos pela DEB/CAPES, editais e portarias adicionais a esses documentos, realizou-se pesquisas bibliográficas com relação à contribuição do PIBID para a formação inicial docente. Por meio dos resultados pôde-se perceber as variadas as formas de apropriações e representações do PIBID, pois através da análise comparativa dos dois materiais diferentes produzidos pelos mesmos entrevistados, assim pudemos localizar que os diversos discursos formulados pelos bolsistas com relação ao programa mudaram de acordo com o material produzido, nos questionários e entrevistas os discentes apontam apenas os pontos positivos do programa, em contrapartida nas redes sociais assumem uma postura crítica com relação ao programa muita vezes negativista assumindo discursos envoltos a formação docente como má remuneração, desprestigio social, até mesmo relatos de violência, apontando problemas com relação à estruturação do programa.
\end{abstract}

Palavras chave: Formação Inicial docente - PIBID- Redes Sociais

\section{THE INTERNET AS AN SOURCE OF ANALYSIS FOR PIBID AND INITIAL TEACHER TRAINING}

\begin{abstract}
Considering the importance which the Institutional Program of scholarship Initiation the teaching (PIBID) has acquired since its creation, with goal to stimulate initial teaching, and contribute with the development and basic education improvement, we objectify in this search highlight the processes and speeches which involve the initial formation teacher training provided by the program produced by the initiation scholars teaching on social networks. However, the analysis here undertaken was done through the application of semi structured questionnaires to initiation scholarship teaching subproject of History, Physics, Chemistry, Mathematics, Biology, Education, Literature, Geography, whose transcription respected the writing of respondents, analysis; materials such as images and present reports in the pages of PIBID Depression internet, and National PIBID Facebook Group.
\end{abstract}


Beyond this methodology we analyze information through the public documents about PIBID, such as: official documents, as management reports issued by DEB/CAPES, additional notices and ordinances to these documents we made a bibliographical search relative to the PIBID contribution to initial teacher formation. By the results it was possible to realize the varied forms of appropriation and representations of PIBID because through comparative analysis of two different materials produced by the same respondents, so we find that the various speeches made by scholars regarding the program changed according with the material produced in questionnaires and interviews the students point out only the positive aspects of the program, on the other hand in social networks take a critical stance on a lot of times oppositional program assuming speeches wrapped teacher training as poor remuneration, social discredit, even reports of violence, pointing out problems regarding the program structure.

Keywords: Teacher Initial Formation - PIBID -Social Networks

\section{INTRODUÇÃO}

O Programa Institucional de Bolsa de Iniciação a Docência - PIBID é um programa que promove bolsas de licenciatura aos estudantes, professores universitários e professores da rede básica participantes de projetos que visam à docência aplicada por Instituições de Educação Superior (IES) em conjunto com escolas de educação básica da rede pública de ensino. O PIBID enquanto programa de repercussão nacional, é representado por meio de diversas páginas, redes sociais, e comunidades participantes do programa, mais do que isso o PIBID encontrou na web uma forma de se representar,e mobilizar sendo inegável a forma de expressão do programa através da internet :

Há muitos sites, blogs, comunidades do Pibid na Web, mostrando uma geração de professores que está mais familiarizada com a produção e o uso de tecnologias contemporâneas. O número de 992.000 resultados no buscador Google mostra o dinamismo das instituições participantes. Importa lembrar que esse número não inclui as novas IES que foram selecionadas pelos editais 2013 (DEB/CAPES, 2013, p.74).

Tomando enquanto ponto de partida essas informações o trabalho traz algumas considerações acerca da formação inicial de professores considerando os saberes docentes promovidos pelo Programa Institucional de Bolsa de Iniciação á Docência, localizando o percurso formativo do programa e as vivências dos pibidianos iniciação á docência dos subprojetos do CFP.

RPIRevista de Pesquisa Interdisciplinar, Cajazeiras, v. 1, Ed. Especial, 63 - 72, set/dez. de 2016. 
Enquanto método optou-se pela aplicação e análise de questionários respondidos pelos bolsistas de iniciação do CFP, e a análise de imagens e relatos presentes nas redes sociais páginas da internet PIBID Depressão, e Grupo público Nacional do PIBID no Facebook. Estes entrevistados que responderam os questionários e são participantes, além da copilação bibliográfica e análise de documentos oficiais públicos que estabelecem as diretrizes do programa, os relatos coletados foram inseridos da mesma maneira como foram escritos no questionário para transparecer o caráter fidedigno da pesquisa. Utilizamos a pesquisa participativa por estarmos inseridas enquanto bolsistas como parte constituinte do programa.

Utilizaremos enquanto referencial teórico para embasar nossas discussões sobre formação de professores: NÕVOA (2009), CAVALCANTE (2009), THOMPSON (2012), CUNHA (2004), entre outros, com a finalidade de refletir a partir de então, sobre os discursos envoltos demandas com relação à iniciação a docência proposta pelo PIBID.

\section{Discursos sobre o PIBID e formação docente inicial do presencial as redes sociais}

Tão importante quanto entender a maneira como o programa é estruturado é também compreender a forma como os sujeitos históricos que o compõem pensam sua participação nele. Compreender a maneira como os bolsistas de iniciação a docência apreendem, os conhecimentos, as dificuldades que são necessários à prática docente, as formas de discursos pelas quais esses discentes articulam diferentes saberes no exercício da docência se constituí enquanto um campo abrangente nas pesquisas.

A formação do educador é um processo acontecendo no interior das condições históricas que ele mesmo vive faz parte de uma realidade concreta determinada que não é estática e definitiva, é uma realidade que se faz no seu cotidiano. Por isso é importante que esse cotidiano seja desvendado (CUNHA,2004,p.36).

Enquanto método inicial de pesquisa para entender esses processos que envolvem esses sujeitos históricos foi escolhido à aplicação de questionários, no total foram realizados 90 questionários e entrevistas orais com bolsistas e ex- bolsistas do CFP dos subprojetos de História, Física, Química, Matemática, Biologia, Pedagogia, Letras, e Geografia, posteriormente foi utilizado o método de análises de depoimentos e publicações virtuais públicas de bolsistas presentes no grupo público do programa presente na rede social 
facebook e da Comunidade virtual PIBID da Depressão, também do facebook. A justificativa pela escolha da página e do grupo para análise ocorreu pelo fato da maioria das pessoas que participaram desta pesquisa enquanto entrevistados são membros do grupo e da comunidade virtual, e os mesmos entrevistados ofereceram levantamentos diferentes que puderam fornecer melhor subsidio para pesquisa.

O primeiro método de coleta de dados abordado foram os questionários de cunho interpretativo, visavam os seguintes questionamentos: Quais os motivos que o impulsionaram a participar do programa? Se ao ingressar no programa o PIBID interferiu nas formas de conceber a docência? Quais os pontos positivos e negativos que identificam na participação do programa? Quais as experiências vivenciadas por estes bolsistas em sala. E permitir um espaço para expressarem por meio de sugestões e opiniões, se concordavam ou não com a forma como o programa é organizado atualmente.

O método de aplicação dos questionários semi estruturados e entrevista orais com bolsistas e ex- bolsistas do CFP foram um método inicial, porém sozinho foi insuficiente para responder às indagações as quais a pesquisa se propõe, assim a análise dos discursos presentes nas redes sociais acabaram por complementa- los fornecendo subsídios aos questionamentos proposto. A aplicação dos questionários e realização das entrevistas foi interessante, porém identificamos que não contribuiu com as questões levantadas pela pesquisa, assim foi adotado outro método de análise. As análises dos questionários serviram para levantar apontamentos com relação à pesquisa. Na escrita do questionário percebemos dos bolsistas um pouco de resistência, vergonha, ou até medo de represálias, por fazerem parte do programa, notamos que os entrevistados tiveram dificuldades de expressarem em seus relatos, questões críticas e posicionamentos com relação ao programa.

Dentre os questionamentos realizados aos bolsistas os que mais chamaram a atenção foram: quais os pontos negativos e positivos que você identifica na participação programa?

\footnotetext{
"Pontos positivos Melhoria no processo de formação docente;

Experiências diversas; Oportunidades de desenvolvimento pessoal e profissional. Ajuda financeira para o investimento em preparação pessoal. Não vejo pontos negativos" (Depoimento de bolsista ID participante do programa do curso de Geografia via questionário).
}

Outro depoimento também seguindo a mesma logica de citar apenas os pontos positivos:

RPIRevista de Pesquisa Interdisciplinar, Cajazeiras, v. 1, Ed. Especial, 63 - 72, set/dez. de 2016. 
"De forma geral me fez crescer enquanto futuro professor assim como pude contribuir para um melhor desenvolvimento da aprendizagem dos alunos. Não me lembro de um ponto negativo." (Depoimento de bolsista ID participante do programa do curso de Química via questionário).

Observa-se que, dos entrevistados $42,7 \%$ apontaram apenas pontos positivos na participação do programa, 28,5 declararam não haver dificuldades ou pontos negativos e outros 28,5\% não responderam a pergunta. Podemos encontrar o gráfico expressando as respostas em porcentagem desta pergunta no anexo I deste artigo. As dificuldades de adquirir respostas dos questionários fizeram nos pensar outra fonte de análise. Por isso, considerando significativa a participação e representação do PIBID, nas redes sociais escolhemos esta fonte para resolver a problemática levantada.

Os discursos analisados aqui são relatos presentes no Grupo Nacional do PIBID História com mais de 20 mil integrantes que integram os subprojetos de todo país e da página criada em 2015 enquanto meio de comunicação e mobilização dos subprojetos e do "PIBID depressão" uma comunidade virtual de mais de 6 mil inscritos, a comunidade "PIBID depressão" se destaca das demais comunidades que envolvem o programa por apresentarem de forma cômica as diversidades vivenciadas no cotidiano dos bolsistas. Através das figuras fictícias "Coordenador Cinzento" e "Bilbo o bolsista" a página retrata por meio de um caráter humorístico situações que muitos dos bolsistas sofrem ao estarem nas escolas. Os relatos analisados são dos mesmos entrevistados que responderam os questionários e participaram da entrevista oral, podemos perceber que ao contrário dos questionários nas redes sociais eles se expressam com mais facilidade com relação às dificuldades enfrentada durante sua formação pelo programa. Dentre os vários relatos analisados dos entrevistados chama -nos a atenção o seguinte relato:

No papel o PIBID é lindo na prática pelo menos na escola sou apenas uma acadêmica de reforço infelizmente!Muitas vezes motivo de chacota entre os demais profissionais!Aplicamos reforço aos alunos por que os ditos professores estão interessados no IDEB e passam alunos sem ao menos saber ler e escrever o próprio nome!(Relato da bolsista de iniciação a docência do subprojeto de Geografia via Grupo Nacional do PIBID)

Podemos encontrar o relato acima na integra no anexo II deste artigo. Ainda no grupo do PIBID Nacional do facebook pudemos ver também vários relatos de bolsistas que presenciaram a violência no espaço escolar, durante a atuação no programa tanto por parte de 
professores como por alunos. Chama atenção dentre relatos, demais bolsistas de iniciação a docência os que revelaram revidar o aluno com violência se fosse agredido diretamente. Esse relato esta presente nos anexo III deste artigo.

È importante salientar que a violência no âmbito escolar existe anteriormente ao PIBID, esta tem sido um fenômeno que tem crescido na contemporaneidade e cada vez mais busca- explicação Abramovay (2002) historicizar um pouco deste trajeto:

Os primeiros estudos brasileiros datam da década de 1970, quando pedagogos e pesquisadores procuravam explicações para o crescimento das taxas de violência e crime. Na década de 1980, enfatizavam-se ações contra o patrimônio, como as depredações e as pichações. Já na maior parte da década de 1990, o foco passa a ser as agressões interpessoais, principalmente entre alunos (ABRAMOVAY, 2002, p.30)

Assim a autora evidencia que a partir do momento que as agressões passam ser consideradas como interpessoais se descobre que os motivos da violência na escola podem ser motivados por questões internas, não apenas por questões externas. Esse tipo de problema vivenciado pelas escolas parceiras interferem diretamente na formação oferecida pelo programa ao bolsista, pois o bolsista atua diretamente neste espaço.

A página "PIBID Depressão" também se fundamenta em um veiculo de perpetuação de variados discursos sobre as dificuldades vivenciadas pelo programa. A reprodução desses discursos ocorre através de cunho humorístico, por meio de foto montagens que utilizam enquanto recursos imagens de séries e programas da televisão populares

As Imagens IV e V (que podem ser encontrada nos anexos deste artigo) representam consecutivamente críticas com relação ao caráter de trabalho coletivo imposto pelo programa aos participantes, discursos de má remuneração e dificuldades de lidar com os alunos realizando uma comparação entre os professores e docentes de iniciação sendo os bolsistas apresentados em uma realidade mais difícil.

O trabalho em grupo é um dos componentes mais valorizados pelo programa os próprios objetivos do mesmo são formulados tendo como base os princípios de NOVOA (2009) que valorizam o trabalho coletivo enquanto troca de experiência e convívio do docente de iniciação com a cultura escolar e a rotina profissional.

No que se referem aos discursos encontrados na página mais do que procurar entender a mensagem que pretende lançar de si, é importante buscar entender as condições de sua formação, como e em que contexto surgiu o que é emitido. Os usuários das redes sociais RPIRevista de Pesquisa Interdisciplinar, Cajazeiras, v. 1, Ed. Especial, 63 - 72, set/dez. de 2016. 
tendem a ser sinceros, pois ao mesmo tempo em que estão expostos se sentem protegidos pelas máscaras das redes sociais.

Os estudos em sites de redes sociais têm pautado, sobretudo, a temática da construção de identidade em rede, que tem processos e características específicos, muitas vezes divergentes, mas complementares em relação à identidade "real". As plataformas digitais têm se apresentado como cenário facilitador da compreensão de como os sujeitos inseridos nesses ambientes (os usuários dos sites de redes sociais) fazem uso das ferramentas disponíveis em redes virtuais para comunicar quem são o que pensam e com o que se identificam (CALVACANTE, 2015, p.223).

A identidade de "pibidianos" e as dificuldades vivenciadas pelos bolsistas são incorporadas pela página de forma cômica e expressada no grupo presente na rede social facebook por meio de discursos: A má remuneração do programa, a indisciplina por parte dos estudantes que não reconhecem os bolsistas de iniciação a docência enquanto professores, crítica ao trabalho em equipe, o sofrimento com prazos de entrega dos relatórios finais, e contato com uma realidade escolar violenta. Diferentemente do que foi visto nos questionários, nas redes sociais são incontáveis os relatos sobre as diversas dificuldades enfrentadas pelos bolsistas no cotidiano escolar.

A construção desses discursos gira em torno do que para a página consiste na identidade Pibidiana, lembrando que todo processo identitário origina-se entre sujeito e sociedade estabelecidas por complexas relações de alteridade. Hall (2001) será esclarecedor deste termo tão complexo ao desenvolver que esta identidade não precisa ser fixa, é instável e consolidada ao longo das vivências.

A identidade surge não tanto da plenitude da identidade que já está dentro de nós como indivíduos, mas de uma falta de inteireza que é "preenchida" a partir de osso exterior, pelas formas através das quais nós imaginamos ser vistos por outros (HALL, 2011, p. 39)

È importante salientar que estas situações provavelmente podem ser realidades inerentes ao programa, mas que de maneira nenhuma desmerecem o seu funcionamento. Considerando as mensagens midiáticas Thompson (2012) esclarece:

Ao interpretar as formas simbólicas, os indivíduos as incorporam na própria compreensão que têm de si mesmos e dos outros. Eles as usam como 
veículos para reflexão e autorreflexão, como base para refletirem sobre si mesmos, os outros e o mundo a que pertencem. (THOMPSON, 2012, p.70).

Esses impasses abrem espaços para reflexões com relação às falas perpetuadas nas redes sociais sobre o programa. Nessa perspectiva as redes sociais principalmente o facebook se propõem enquanto uma forma de promover o diálogo referente à formação docente que é o objetivo primordial do programa se estabelecendo enquanto fonte de discussão.

\section{Considerações Finais}

As redes sociais consistem em amplo núcleo de análise para configurar os aspectos ligados a formação docente, pois a partir deste meio é possível obter uma participação mais efetiva dos entrevistados. As dificuldades e discursos elencados apontam subsídios para repensar algumas práticas, referente ao programa. Um âmbito muito interessante por que esses enunciados apenas são levantados pelos bolsistas em ambientes informais como redes sociais. Refletir com relação à formação inicial e ao programa consiste em rever as próprias práticas. Os relatos, discursos e dificuldades vivenciadas cotidianamente demarcam experiências significativas para a formação docente. E assim mesmo identificando essas dificuldades pode se evidenciar a importância do PIBID na formação dos bolsistas de ID, principalmente com as análises realizadas, com os relatos fornecidos pelos subprojetos.

O conjunto de discussões realizadas apontou um uma série de discursos e aspectos referente ao PIBID, deixando em evidência diversos pontos que necessitam de análise, demonstrou o seu caráter de cunho virtual, seu modelo formativo, o nível de organização das atividades, envolto a isso lacunas e pontos de análise que esperamos ainda serem preenchidas com novos trabalhos e leituras sobre o tema.

\section{REFERÊNCIAS}

ABRAMOVAY, M. O bê-a-bá da intolerância e da discriminação. Brasília, DF: UNICEF, 2002. Disponível em: www.unicef.org/brazil/pt/Cap_02.pdf. Acesso em: 18 mar. 2014. CAVALCANTE, Andrea Pinheiro Paiva; MONTEIRO, Maria Clara Sidou, CARNEIRO Jessica; SALES, João Victor. Suricate Seboso no Facebook: linguagem, identidade e RPIRevista de Pesquisa Interdisciplinar, Cajazeiras, v. 1, Ed. Especial, 63 - 72, set/dez. de 2016. 
memória do Nordeste. In: Revista Rio de Janeiro, v.11, n.1, p. 223-232, maio 2015.

Disponível em: http://revistaberro.com/edicoes/revistaberro_ano01_n02_agosto-setembro2014.pdf. Acesso em: 14 de fev de 2016.

CUNHA, Maria Isabel. Inovações: conceitos práticas. In: CASTANHO, Sérgio;

CASTANHO, Maria Eugênia L.M (Orgs). Temas e textos em metodologia do ensino superior. Campinas: Papirus, 2004.

DEB/CAPES. Relatório de Gestão. Brasília, 2013

Grupo nacional do facebook. Disponível em:<

https://www.facebook.com/groups/1600686786872263/?fref=ts $>$ Acesso em: $<28$ maio 2016>.

NÓVOA, António. Para uma formação de professores construída dentro da profissão.

Revista Educación, n. 350, set.-dez. 2009. Disponível

em: $\left\langle w w w . r e v i s t a e d u c a c i o n . e d u c a c i o n . e s / r e 350 / r e 350 \_09\right.$ por.pdf $>>>>$. Acesso em: 15 maio. 2016.

PIBID Depressão. Disponível em: $<$ https://www.facebook.com/PIBID-da-

Depress\%C3\%A3o-618391631520019/?fref=ts $>$. Acesso em: $<28$ maio 2016>.

THOMPSON, John. A mídia e a modernidade: uma teoria social da mídia. 13. ed.

Petrópolis: Vozes, 2012.

\section{ANEXOS}

Anexo 1-Gráfico apontando o número de entrevistados que somente apontaram pontos positivos nas vivências do programa.

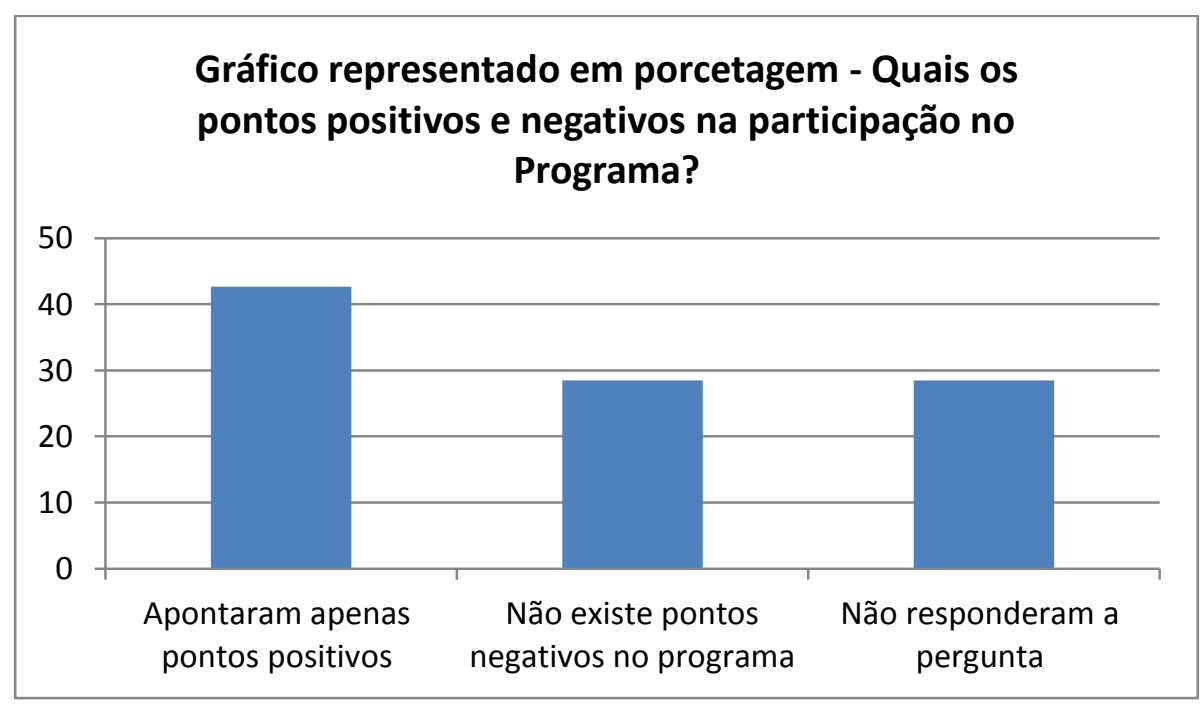

RPIRevista de Pesquisa Interdisciplinar, Cajazeiras, v. 1, Ed. Especial, 63 - 72, set/dez. de 2016. 
Anexo II: Imagens de depoimentos de bolsistas iniciação docência. Fonte Grupo Nacional.

Nowine Pareitu Cunvoea No papel o Pibid é lindo na prática pelo

menos na escola sou apenas uma acadêmica de reforço infelizmente!!! Muitas vezes motivo de chacota entre os demais profissionais!!! Aplicamos reforço aos alunos porque os ditos professores estão interessado no IDEB e passam alunos sem ao menos saber ler e escrever o próprio nome!!

Descurtir - Responder - 131 - 9 de abril às 21:55

Anexo III: Imagens de depoimentos. Fonte :Grupo Nacional do PIBID

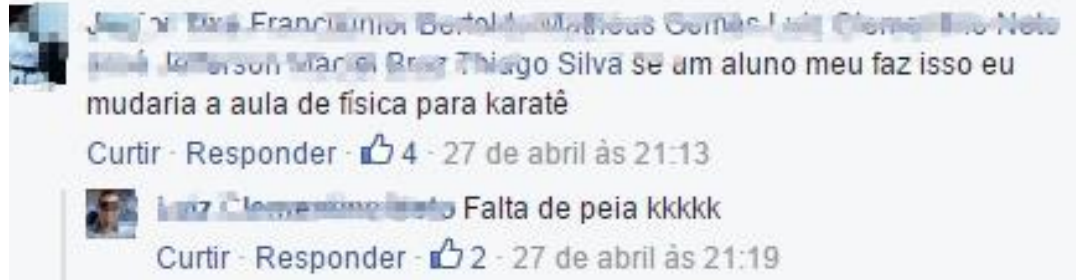

Anexo IV e V: Imagens Pibidianos em uma situação que indica má remuneração e cansaço. Critica ao trabalho em grupo. Fonte grupo PIBID Depressão.
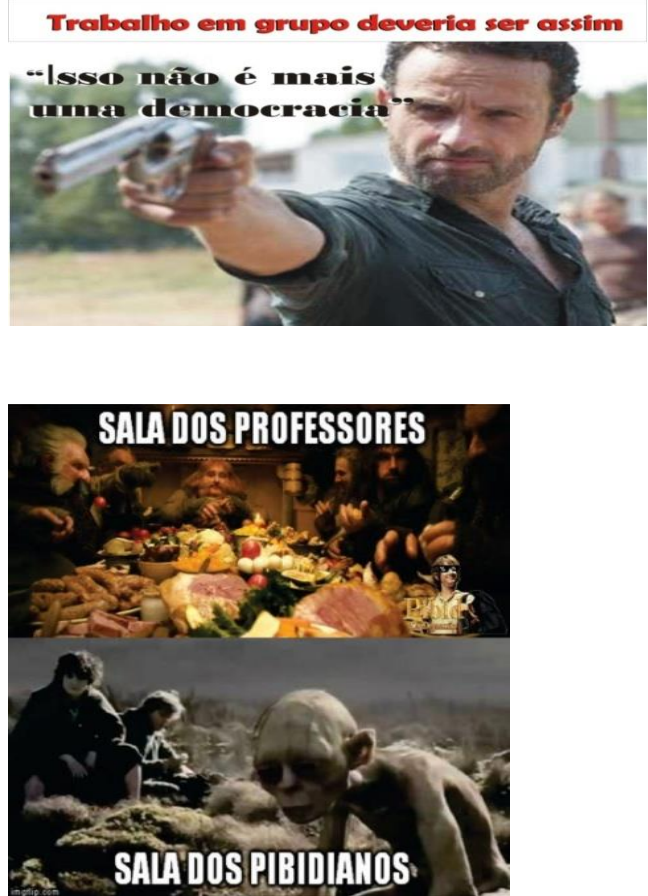

RPIRevista de Pesquisa Interdisciplinar, Cajazeiras, v. 1, Ed. Especial, 63 - 72, set/dez. de 2016. 